\title{
Pandemi Sürecinde Büyükşehir Belediyelerinin Halkla İlişkiler Aracı Olarak Sosyal Medya Kullanımı ${ }^{1}$
}

\author{
DOI: $10.26466 /$ opus. 898016 \\ $*$ \\ Serife Pekküçükșen* - Balı Yıldırım** \\ *Doç. Dr., Karamanoğlu Mehmetbey Üniversitesi, İ̈BF, Karaman/Türkiye \\ E-Posta: serifepotuk@yahoo.com \\ ORCID: $\quad \underline{0000-0003-2244-2646}$ \\ **Uzm., Karamanoğlu Mehmetbey Üniversitesi, Sosyal Bilimler Enstitüsü, Karaman/Türkiye \\ E-Posta: baliyildirim3@gmail.com \\ ORCID: $\quad \underline{0000-0002-3206-9542}$
}

Öz

Vatandaşları günlük faaliyetlerinden haberdar etmek, yeni projeler hakkında vatandaşların görüşlerini almak ve faaliyet alanları ile ilgili konularda bilgilendirmek için yerel yönetimlerde halkla ilişkiler önem taşımaktadır. Çağın gereklerine uygun olarak yerel yönetimlerde halkla ilişkiler faaaliyetlerinin yürütüldü̈̆̈̈ mecralar da farklılaşmış ve sosyal medya kullanımı yaygınlaşmıştır. Bu çalı̧̧manın amacı Covid-19 pandemi döneminde büyükşehir belediyelerinin halkla ilişkiler faaliyetlerinde sosyal medya kullanma sıklıklarını ortaya koymaktır. Çalışma halkı bilgilendirmek ve yönlendirmek adına kamu kurumlarının sosyal medyayı kullanımlarının değerlendirilmesi açısından önem arz etmektedir. Araştırmada büyükşehir belediyelerinin pandemi dönemini kapsayan 13 Mart - 01 Haziran 2020 tarih aralı̆̆ında Twitter üzerinden yaptıkları paylaşımlar, NCapture uzantısıyla Nvivo programına uygun verilere dönüştürülmüss ve bu veriler nitel bir çerçevede analiz edilerek belirli kategoriler altında sınıflandırılmıştır. Ayrıca en fazla paylaşım yapan üç belediyenin "WordCloud" görünümleri oluşturulmuş ve incelenmiştir. Analiz sonucunda sosyal medyayı tüm büyükşehir belediyelerinin aktif olarak kullandığ çok yer verildiği ve bunun yanında tüm belediyelerin koronavirüs temasıyla ilgili paylaşımlar yaptı̆̆ görülmüştür. WordCloud görünümler ise kategorilerin ağırlkkları ile uyumlu sonuçlar vermiştir. Sonuç olarak büyükşehir belediyelerinin sosyal medyayı iletişim ve halkla ilişkiler aracı olarak aktif bir şekilde kullandıkları ve koronavirüs temasına sıklıkla yer verdikleri varsayımları desteklenmiştir.

Anahtar Kelimeler: Halkla İlişkiler, Yerel Yönetimler, Büyükşehir Belediyeleri, Twitter, Covid19.

\footnotetext{
${ }^{1}$ Bu çalışma "Kamuda Halkla ilişkiler Sürecinde Bir Araç Olarak Sosyal Medya Kullanımı: Covid-19 Pandemi Döneminde Büyükşehir Belediyeleri Üzerinden Bir Analiz" isimli yüksek lisans tezinden üretilmiştir.
} 


\title{
The Use of Social Media as a Public Relations Tool During the Pandemic by Metropolitan Municipalities
}

$*$

\begin{abstract}
Public relations are important in local governments in order to inform citizens about their daily activities, to get their views on new projects and to inform them about their fields of activity. In accordance with the requirements of the age, the media where public relations activities are carried out in local governments have also differentiated and the use of social media has become widespread. The aim of the study is to reveal the frequency of using social media in the public relations activities of metropolitan municipalities during the Covid-19 pandemic period. The study is important in terms of evaluating the use of social media by public institutions in order to inform and guide the public. In the study, the shares of metropolitan municipalities on Twitter between the process on March 13th - June 01st 2020 were transformed into data suitable for NCapture extensions Nvivo program, and these data were analyzed and classified under certain categories. In addition, the "WordCloud" views of the three most shared municipalities were created and analyzed. In the result of the analysis, it was seen that all metropolitan municipalities have actively used the social media, "Retweet from the Mayor" and "Corporate Activity" categories have been mentioned more in the posts, as well as all the municipalities has shared post with the coronavirus theme in the related process. WordCloud views also gave coherent results with the severity of the categories. As a result, the assumptions that metropolitan municipalities actively use social media as a communication and public relations tool and that they often include the coronavirus theme are supported.
\end{abstract}

Key Words: Public Relations, Local Governments, Metropolitan Municipalities, Twitter, Covid19. 


\section{Giriş}

İnsanların yöneten yönetilen, satıcı alıcı gibi karşılıklı iletişimde bulunmaya başladıkları dönemlerden beri var olan halkla ilişkiler günümüzde önemli bir alan olarak gelişimini sürdürmeye devam etmektedir. Kitleleri etkileyen küresel çaplı olaylar halkla ilişkilerin dönüm noktaları olup, bu dönüm noktalarından en önemlisi iletişim teknolojilerindeki gelişmelerdir. Teknolojinin iletişim araçları üzerinde hızlı bir gelişim göstermesi, halkla ilişkiler uygulamalarını dijital ortama taşımış ve halkla ilişkiler adına yeni değişimleri beraberinde getirmiştir.

Teknolojik gelişmelerin hiz kazanmasıyla küreselleşen dünyada rekabet hat safhaya ulaşmıştır. Bu rekabet ortamının oluşması halkla ilişkiler uygulamalarını ihtiyaçtan öte zorunluluk haline getirmiş ve artan iletişim olanakları halkla ilişkilerin uygulanabilirliğini arttırmıştır. Yaygın uygulanabilirlik alanlarında özellikle internet, entegre medya özelliğiyle birlikte ucuz, hızlı ve karşılıklı iletişime olanak sağlayan yönüyle teknolojinin halkla ilişkilere sunduğu en önemli ve en gelişmiş iletişim aracıdır. Halkla ilişkilerin amacı olan tanıma, tanıtma ve karşılıklı iletişimi, ulaştığı büyük kitlelerde uygulama şansı sunan internet, halkla ilişkiler adına yeni bir penceredir. İnternetin sunduğu fırsatları değerlendirmek isteyen örgütler halkla ilişkiler çalışmalarını dijital ortama kaydırmaktadır. Örgütlerin bu amaçla dijital ortamda kullandıkları en önemli araçların başında sosyal medya platformları gelmektedir. Günümüzde sosyal medya platformları hedef kitlelerin aktif olarak kullanıp sürekli iletişim halinde oldukları platformlardır ve kitle iletişimine olanak sağlaması açısından ön plana çıkmaktadır. Sosyal medya araçları gelişen teknolojiyle şekillenmekte ve değişmektedir. Bu değişim içerisinde hem kamu kurumları hem özel sektör örgütleri yerlerini almaktadır.

Devletlerin kamu yönetimi örgütlenmelerinde yer alan yerel yönetim birimleri halkla ilişkilere en çok ihtiyaç duyan kamu kurumlarıdır. Bu ihtiyaç yerel yönetimlerin merkezi yönetim ve halk arasında bir yerde bulunmasından kaynaklanmaktadır. Merkezi yönetimin en alta ulaşmasında ve halkın da merkezi örgüte taleplerini iletmesinde yerel yönetimler önemli bir paya sahiptir. Bu görevlerin yanında yerel yönetimlerin halka yakın olmaları ve günümüzde artan katılımcı 
demokrasi talepleri halkla ilişkileri yerel yönetimlerde zorunlu kılmaktadır. Bunların dışında halkın merkezi yönetim de dâhil olmak üzere yönetime gösterdiği tepkinin ve yönetimden beklediği geri bildirimin muhatabı yine yerel yönetim birimleridir. Bu durum yerel yönetimlerin halkla güçlü bir iletişim kurmasını zorunlu kılmaktadır. Günümüzde yerel yönetim birimleri bu iletişimi sağlıklı ve verimli yapabilmek adına profesyonel anlamda halkla ilişkiler uygulamaları yürütmektedir. Bu amaçla yürütülen faaliyetlerin sosyal medya ayağı ise bu çalışmada değerlendirilmeye alınacak husustur.

Sosyal medyanın halkla ilişkiler alanı ve yerel yönetimlerin halkla ilişkiler uygulamalarındaki etkisi göz önünde bulundurularak çalışmada ilk olarak halkla ilişkiler, yerel yönetimler ve sosyal medya kavramları üzerinde durulacak ve aralarındaki bağlantıya değinilecektir. Daha sonra Türkiye'deki büyükşehir belediyelerinin halkla ilişkiler aracı olarak sosyal medyayı kullanma düzeyleri irdelenecektir. Büyükşehir belediyelerine ait sosyal medya hesaplarından yapılan paylaşımlar analiz edilerek, büyükşehir belediyelerinin sosyal medya örgütlenmeleri, hedef kitleden gelen geri bildirimlerin yoğunluğu ve bu geri bildirimlerin ne ölçüde değerlendirildiği açıklanmaya çalışılacaktır.

\section{Yerel Yönetimlerde Halkla İlişkiler}

Halkla ilişkiler ne olduğu ve ne olması gerektiği konusunda birçok görüş bulunan bir kavramdır. Aslında ne olması gerektiği konusunda tartışmaların sürmesi kavramın sürekli bir devinim içinde olduğunu göstermektedir. Bu da tanım çokluğuna neden olmaktadır. Bu kavram yoğunluğunda halkla ilişkileri tanımlamaya deyimin içerdiği "halk" kelimesinden başlamak doğru bir yaklaşım olacaktır. Deyimdeki teknik anlamıyla halk, örgütün eylem ve faaliyetlerinden etkilenen, kanaat ve davranışlarıyla örgütü etkileyen, ortak çıkarlara sahip insan topluluğudur. Bu açıyla bakıldığında halkla ilişkiler de örgütün bu insan topluluğuyla arasındaki etkileşimi ifade etmektedir (Mihçığlu, 1970, s.92).

Tanım olarak halkla ilişkiler kavramına bütün olarak bakıldığında; özel ya da tüzel kişilerin belirtilmiş kitlelerle dürüst ve sağlam bağlar kurup geliştirerek onları olumlu inanç ve eylemlere yöneltmesini, 
tepkileri değerlendirerek tutumuna yön vermesini ve karşıllklı yarar sağlayan ilişkiler sürdürme yolundaki planlı çabaları kapsayan bir yöneticilik sanatı olarak tanımlanabilir (Asna, 2006, s.23). Tanımdan hareketle halkın zihninde olumlu izlenim bırakmak, halkla ilişkilerin amacı; halkın tepkilerine göre politika üretilmesi ise halkla ilişkilerin sonucu olarak görülebilir. Dolayısıyla her örgütün kendi "halk" tanımını kapsayan insan topluluğunu belirleyip o alanda uzmanlaşmaya mecbur olduğu söylenebilir.

Halkla ilişkiler kamu kurumları çerçevesinde değerlendirildiğinde; örgüt olarak kamu kurumlarının -deyimdeki teknik anlamıyla- 'halkı' doğrudan vatandaştır. Vatandaşa en yakın resmî kurumlar ise yerel yönetim birimleridir. Yerel yönetim birimleri merkezi yönetimin sorumluluğu dışındaki belirli alanlarda yaşayan bireylere hizmet sağlamak amaciyla kurulmuştur.

Yerel yönetimlerde halkla ilişkiler ihtiyacını ortaya çıaran birçok etmen vardır. Eryılmaz (2017), yönetimin isabetli karar vermek adına karar sonrası doğacak hizmetten yararlanacak bireylerin düşünce ve eğilimlerine ihtiyaç duyacağını ve bunu sağlamanın en basit yolunun halkın yönetime demokratik katılımının sağlanması olduğunu belirtmektedir. $\mathrm{Bu}$ çerçevede halkın düşünce ve eğilimlerini öğrenme yollarından birisi de halkla ilişkiler faaliyetleridir. Seçim dönemi ya da halkın yönetimde görev alması gibi yolların dışında halkla ilişkiler faaliyetleri, yönetimi başarıya ulaştıracak görüşleri halktan toplamak adına önemli bir araçtır. Halkla ilişkiler ihtiyacını ortaya çıaran bir diğer etmen, yerel yönetimlerin hedef kitlenin kontrolüne açık olmasıdır. Özellikle fiziksel hizmetlerde halka yakın olunması, halkın karar alma ve bu kararı yürütme sürecine katılma iştahını kabartmaktadır. Dolayısıyla seçim dışı katılımcı demokrasiyi yürütme görevi de halkla iç içe olan yerel yönetimlere kalmıştır. Bu kapsamda yerel yönetimlerin halkla ilişkiler ihtiyacı, hizmetlerin hedef kitleye aktarılmasının yanında seçim dışı katılımcı demokrasinin de yürütülmesini sağlamaktır (Karadeniz, 2008, s.106).

$\mathrm{Bu}$ etmenlerin dışında, yerel yönetimlerde yöneticilerin halk tarafından seçilmesi ve doğrudan doğruya bölge halkına yönelik hizmet üretilmesi, yerel yönetimlerde halkla ilişkileri zorunlu kılmaktadır. Yerel yönetim birimlerinin başarısı yürütülen halkla ilişkiler faaliyetlerinin 
başarısıyla doğru orantılıdır. Etkili bir örgütlenmeye sahip yerel idareler şüphesiz halkla ilişkiler uygulamalarında başarıya ulaşacaktır. Yerel yönetim birimlerinde halkla ilişkilerin temel amaçları şöyle siralanmaktadır (Tortop ve Özer, 2017, s.233-234):

- Vatandaşları yerel kuruluşun politikasından ve günlük faaliyetlerinden haberdar etmek,

- Yerel kuruluşlar tarafından kesin kararlar alınmadan önce, önemli yeni projeler hakkında vatandaşlara görüşlerini belirtme firsatı vermek,

- Yerel kuruluşun işleyiş sistemi ile kendi hak ve sorumlulukları konusunda vatandaşları aydınlatmak,

- Vatandaşlık gururunu aşılamak ve geliştirmek.

Yerel yönetimlerde ve dahi kamu yönetiminde halkla ilişkilerin temel amaçları içerisinde burada belirtilmeyen kurum içi fonksiyonları da önemlidir. Halkla ilişkiler kurum içi ast üst ilişkilerini iyileştirip etkili bir iletişim ağı kurarak kurumun etkinliğini arttırmaktadır. Kurumlarda halkla ilişkiler sayesinde oluşan etkili iletişim, yöneticilerin doğru değerlendirmeler yaparak doğru kararlar almalarını ve iyi planlama yapmalarını sağlamaktadır (Selvi ve Şentürk, 2019, s.338).

Yerel yönetimlerde halkla ilişkilerin diğer bir önemi de geri bildirimdir. Geri bildirim olarak halkın tepkisi ve isteklerinin öğrenilmesine herkesten çok yerel yönetimler ihtiyaç duyar. Yine aynı şekilde halk, şikâyetlerini merkezi yönetime göre yerel yönetim birimlerine daha çabuk iletebilir ve buna göre işlem yapılmasını yine yerel yönetim birimlerinden bekler. Bu kapsamda özellikle seçimle yönetime gelen ve sürekli halkın desteğine ihtiyacı olan yöneticilerin halk ve kuruluşlar arasındaki bu ilişkiyi korumak adına halkla ilişkilere önem vermesi gerekmektedir (Karadeniz, 2008, s.109).

Genel çerçeveden bakıldığında yerel yönetimlerin halkla ilişkiler adına doğal yaşam alanı olduğu ve yerel yönetimin kendine has özelliklerinin halkla ilişkilerle bütünlük içinde ilerlediği görülmektedir. Yıldırım (2015), yerel yönetimlerin gerekliliklerine değinirken; yerel yönetimlerin aktif yurttaşlığı geliştirmesine, halka hesap sorma yönetime hesap verme sorumluluğu aşılamasına, yerel temsili ve katılımı sağlamasına ve merkez ile halk arasında iletişim aracı olmasına 
değinmektedir. Tüm bu sayılan görevler yerel yönetimlerin doğal halkla ilişkiler sürecinin bir parçasıdır.

\section{Halkla İlişkiler Aracı Olarak İnternet ve Sosyal Medya}

Yerel yönetimler sağlıklı bir halkla ilişkiler süreci yürütmek adına birçok araç kullanmaktadır. Bir çalışanın herhangi bir hedef kitle mensubuyla girdiği sözlü diyalogdan dağıtılan afişlere kadar her türlü iletişim unsuru halkla ilişkiler aracı olarak düşünülebilir. Ancak burada çalışmanın konusunu oluşturan internet ve sosyal medya platformlarına değinmek yerinde olacaktır.

Başlangıçta savunma amaçlı geliştirilen internet ağı günümüzde bilgiye ulaşma, eldeki bilgiyi yayma ve iletişim amaçlı kullanılmaktadır. Karşılıklı iletişimin olduğu her yerde doğal olarak halkla ilişkiler de mevcuttur. Ancak internetin halkla ilişkilere etkisi bununla sınırlandırılamayacak kadar önemlidir. İnternet, halkla ilişkilerin kolaylaşmasını ve yaygınlık kazanmasını sağlayan en önemli olgulardan birisi olmuştur. Halkla ilişkileri reklam ve propagandadan ayıran en önemli özelliği karşılıklı iletişimin olmasıdır. İnternet ile birlikte halkla ilişkiler uygulamasında yavaş işleyen hedef kitleye bilgi aktarılması ve sonuçların toplanması süreci hız kazanmış ve karşılıklı iletişim sürekli hale gelmiştir. Bu kapsamda karşılıklı iletişime imkân sağlayan internet halkla ilişkilerin diğer alanlarla karışmasının önüne ket vurmuştur. Bunun dışında internet, halkla ilişkilerde gerekli olan birçok işlevi daha avantajlı bir şekilde yerine getirmektedir. Bu açıdan internet halkla ilişkiler çalışmalarında doğru kullanılıp stratejik bir araç olarak değerlendirilmelidir (Aydın ve Taş, 2016, s.112).

Grunig, yeni medyanın geleneksel medyaya göre stratejik halkla ilişkiler yönetimine daha uygun olduğunu ve uygulamada mükemmelliğin yakalanacağını savunmaktadır. Yeni medya ve halkla ilişkilerin özellikleri birbiriyle uyumlu olsa da mükemmelliği yakalamak adına, dijital halkla ilişkiler uygulamalarını geleneksel yollarla yapmak çalışmaları başarısızlığa itecektir. Web 1.0 döneminde internet halkla ilişkiler özelinde bilgiyi yaymak ve haber bültenleri paylaşmak gibi amaçlarla kullanılmış, ancak web 2.0 dönemiyle internet dijital medyayı oluşturmuş ve dijital halkla ilişkiler çalışmalarının da güncellenmesi 
gerekmiştir. Grunig (2009), günümüzde birçok halkla ilişkiler uygulayıcısının bu ayrımı göz ardı ettiğine ve sosyal ağ siteleri üzerinden yürütülen çalışmaların pazarlamaya daha yakın olduğuna değinmektedir. Dijital medya üzerinden yapılan çalışmaların güncellenmemesi durumunda internet halkla ilişkiler için faydalı bir araç olmaktan çıkacaktır.

Etkili bir iletişim aracı olmalarının yanında internet ve sosyal medya, halkla ilişkileri hem teorik hem de uygulamada olumlu yönde etkilemektedir. Öyle ki halkla ilişkiler birimleri internet ile birlikte kendi istek ve arzularına göre doğrudan kontrol edebilecekleri kitle ile iletişimde etkili bir iletişim aracına sahip olmuşlardır. Bu sayede hedef kitle ile maliyetsiz ve süre kısıtlaması olmadan istedikleri zaman birebir karşılıklı iletişim imkânı bulmuşlardır. Bunun yanında internet üzerinden yapılan halkla ilişkiler çalışmalarının herkese açık ve sürekli erişilebilir olması, kurumların şeffaflık, açılık, dürüstlük, hesap verebilirlik ve güvenilirlik gibi ilkelere daha çok önem vermelerini gerekli kılmıştır. Bu ilkeler çerçevesinde yürütülen halkla ilişkiler çalışmalarının daha başarılı olacağı varsayımından hareketle; internetin, ilkelere uyma zorunluluğu çerçevesinde halkla ilişkilere dolaylı olarak olumlu etki ettiği söylenebilir.

İnternet tabanlı kullanılan tüm ağların detaylı ve güncel verilerini içeren We Are Social (2020) raporuna göre; Türkiye' de aktif olarak soysal medya kullanan 54 milyon nüfusun \%99'u sosyal medyaya erişmek için mobil telefon kullanmaktadır. Masaüstü veya dizüstü bilgisayar gibi diğer araçlardan sosyal medya kullanımı önceki yılın Ocak ayına göre \%49 azalmıştır. Türkiye'de mobil telefon kullanımı çok yüksek olduğu için aşağıdaki tabloya burada değinmek yerinde olacaktır.

Tablo 1. 2019'da Türkiye'de Telefondan En Çok Kullanılan 10 Uygulama

\begin{tabular}{lll}
\hline Sira & Uygulama Ad1 & Şirket \\
\hline 1 & Whatsapp Messenger & Facebook \\
2 & İnstagram & Facebook \\
3 & Facebook & Facebook \\
4 & Facebook Messenger & Facebook \\
5 & Twitter & Twitter \\
6 & Sahibinden.com & Sahibinden \\
7 & E-Devlet & T.C. Ulaştırma ve Altyapı Bakanlığ \\
8 & Ziraat Mobil & Ziraat Bankası \\
9 & Letgo & Letgo \\
10 & Hepsiburada & Hepsiburada.com \\
\hline
\end{tabular}


Kaynak: We Are Social, Ocak 2020.

Tablo 1'de görüldüğü gibi mobil telefon üzerinden en çok kullanılan uygulamalarda sosyal medya araçları başat durumdadır. Bu durum Türkiye özelinde hedef kitleye ulaşmadaki en etkili halkla ilişkiler aracının sosyal medya olduğunu göstermektedir.

\section{Araştırmanın Amacı}

Çalışmanın amacı, "sosyal medya platformlarının, büyükşehir belediyelerinin halkla ilişkiler uygulamalarındaki yerinin ne olduğu, hedef kitleye bu platformlar aracılığıyla ne ölçüde ulaşıldığg ve geri bildirimlerin ne düzeyde olduğu?" sorusundan hareketle; büyükşehir belediyelerinin halkla ilişkiler aracı olarak sosyal medya kullanımlarını pandemi süreci özelinde değerlendirmektir.

\section{Varsayım ve Sınırlılıklar}

Çalışma temel olarak "büyükşehir belediyelerinin halkla ilişkiler aracı olarak sosyal medyayı kullandıkları" varsayımına dayandırılmıştır. İkinci varsayım ise "büyükşehir belediyelerinin beklenmedik ve olağanüstü bir durum olarak ortaya çıan pandemi döneminde sosyal medyayı daha aktif olarak kullandıkları" varsayımıdır.

Çalışmanın sınırlılıkları da mevcuttur. Bu sınırlılıklar;

Sosyal medyanın yerel yönetimlerdeki yerini belirlemede inceleme kolaylığı sağlaması açısından belirli bir dönemin seçilmesi zorunluluğundan dolayı çalışma süreci Covid-19 pandemi dönemiyle sinırlandırılmıştır. Bu örneklem daha da kısıtlanarak 13 Mart-01 Haziran 2020 tarihleri arasına indirgenmiştir. İlgili tarih aralığının belirlenme sebebi ise pandemi dönemindeki ilk kısıtlama süreci olması ve Covid-19 pandemisinin en etkili gündem olduğu süre zarfı olmasıdır.

Twitter, yapılan araştırmalarda kitlesel olaylarla en çok ilişkili sosyal medya aracı olarak görülmektedir (Vicari, 2012, s.280). Bu nedenle sosyal medya platformlarından sadece Twitter verileri temel alınmıştır. 


\section{Evren ve Örneklem}

Araştırmanın evrenini yerel yönetim birimleri oluşturmaktadır. Evrenin belirlenmesinde halka yakın olma ve halkla iletişim kurma ihtiyacının daha fazla olma kriterleri göz önünde bulundurulmuştur.

Çalışmanın örneklemini internet olanaklarını ve sosyal medyayı daha yaygın kullanabiliyor oldukları varsayımı ve inceleme kolaylığı sağlaması açısından büyükşehir belediyeleri oluşturmaktadır.

\section{Çalışmanın Yöntemi}

Çalışmada 30 büyükşehir belediyesinin 13 Mart-01 Haziran 2020 tarih aralığında Twitter üzerinden yaptıkları paylaşımlar Twitter Advenced Search Browser üzerinden görüntülenmiştir. Her belediye adına özel olarak derlenen bu paylaşımlar NCapture uzantısı kullanılarak doğrudan Nvivo programına aktarılmıştır.

Araştırmanın nicel ayağında, Nvivo programı üzerinden büyükşehir belediyelerinin ilgili tarihler arasında Twitter üzerinden yaptıkları paylaşım sayıları listelenmiştir. Nitel anlamda, örnek olarak 3 belediyenin verileri incelenerek kategoriler belirlenmiş ve tüm paylaşımlar bu kategoriler altında sınıflandırılarak analiz yapılmıştır. Ayrıca daha fazla verinin daha doğru sonuç vereceği varsayımıyla en fazla paylaşım yapan üç belediye adına WordCloud görünüm elde edilmiştir. 


\section{Bulgular}

Tablo 2. Büyükşehir Belediyeleri Tweet Sayıları Karşılaştırması

\begin{tabular}{|c|c|c|c|}
\hline Belediye & $\begin{array}{l}24 \text { Aralık-13 Mart } \\
\text { Arası Atılan Tweet } \\
\text { (80 Gün) }\end{array}$ & $\begin{array}{l}13 \text { Mart-01 Haziran } \\
\text { Arası Atılan Tweet } \\
\text { (80 Gün) }\end{array}$ & Fark $(\%)$ \\
\hline Aydın & 54 & 58 & 7.4 \\
\hline Balıkesir & 139 & 276 & 98.5 \\
\hline Bursa & 319 & 420 & 31.6 \\
\hline Denizli & 218 & 404 & 85.3 \\
\hline Diyarbakır & 571 & 790 & 38.3 \\
\hline Erzurum & 175 & 222 & 26.8 \\
\hline Eskişehir & 250 & 309 & 23.6 \\
\hline Gaziantep & 397 & 821 & 106.8 \\
\hline Hatay & 299 & 344 & 15 \\
\hline İstanbul & 307 & 700 & 128 \\
\hline İzmir & 281 & 374 & 33 \\
\hline Kahramanmaraş & 679 & 792 & 16.6 \\
\hline Kayseri & 311 & 453 & 45.6 \\
\hline Konya & 266 & 471 & 77 \\
\hline Malatya & 496 & 528 & 6.4 \\
\hline Manisa & 122 & 268 & 19.6 \\
\hline Mardin & 1008 & 938 & -7 \\
\hline Mersin & 217 & 232 & 6.9 \\
\hline Muğla & 67 & 177 & 164.1 \\
\hline Ordu & 229 & 349 & 52.4 \\
\hline Sakarya & 439 & 494 & 12.5 \\
\hline Samsun & 186 & 293 & 57.5 \\
\hline Şanlıurfa & 744 & 690 & -7.3 \\
\hline Tekirdağ & 255 & 239 & -6.3 \\
\hline Trabzon & 252 & 361 & 43.2 \\
\hline Van & 401 & 317 & -21 \\
\hline Toplam & 8682 & 11320 & 30.3 \\
\hline
\end{tabular}

Tablo 2'de büyükşehir belediyelerinin 13 Mart-01 Haziran 2020 tarihleri arasındaki tweet sayılarına ve bu tarih aralığından önceki aynı süreye karşılık gelen 80 günlük dönemdeki tweet sayılarına yer verilmiştir. Tabloda yer almayan büyükşehir belediyelerinin 24 Aralık 2019-13 Mart 2020 tarihleri arasındaki tweetlerine erişilememiştir. Bunların dışındaki 26 belediyeden sadece 4 belediyede tweet sayıları önceki döneme göre düşüş göstermiştir. Toplam tweet sayılarında ise $\% 30,3^{\prime} l u ̈ k$ bir artış görülmektedir. Bu tablodan hareketle pandemi döneminde büyükşehir belediyelerinin Twitter'ı daha aktif kullandıkları söylenebilir. 
Tablo 3. Büyüksşehir Belediyeleri Takipçi Sayıları

\begin{tabular}{|c|c|c|c|c|}
\hline \multirow[t]{2}{*}{ Büyükşehir Belediyesi } & \multicolumn{2}{|c|}{13 Mart 2020 TakipçiPaylaşılan } & \multirow{2}{*}{$\begin{array}{rr}\text { Tweet01 } & \text { Haziran } \\
\text { Takipçi Sayısı }\end{array}$} & \multirow[t]{2}{*}{ 2020Artış (Yüzde) } \\
\hline & Sayıs1 & Sayıs1 & & \\
\hline Adana & 67792 & 240 & 78881 & 16 \\
\hline Ankara & 788843 & 893 & 850286 & 7 \\
\hline Antalya & 257502 & 205 & 274508 & 6 \\
\hline Aydın & 38183 & 58 & 45931 & 20 \\
\hline Balıkesir & 16931 & 276 & 21549 & 27 \\
\hline Bursa & 259070 & 420 & 270089 & 4 \\
\hline Denizli & 18591 & 404 & 24206 & 30 \\
\hline Diyarbakır & 38904 & 790 & 45771 & 17 \\
\hline Erzurum & 33813 & 222 & 36864 & 9 \\
\hline Eskişehir & 76539 & 309 & 90381 & 18 \\
\hline Gaziantep & 111783 & 821 & 131589 & 17 \\
\hline Hatay & 37111 & 344 & 43859 & 18 \\
\hline İstanbul & 1108517 & 700 & 1220910 & 10 \\
\hline İzmir & 282105 & 374 & 326074 & 15 \\
\hline Kahramanmaraş* & & 792 & & \\
\hline Kayseri & 42332 & 453 & 47304 & 11 \\
\hline Kocaeli & 61043 & 937 & 70738 & 15 \\
\hline Konya & 199725 & 471 & 216607 & 8 \\
\hline Malatya & 22952 & 528 & 26835 & 16 \\
\hline Manisa* & & 268 & & \\
\hline Mardin* & & 938 & & \\
\hline Mersin & 30905 & 232 & 40340 & 30 \\
\hline Muğla & 23774 & 177 & 30821 & 29 \\
\hline Ordu & 21086 & 349 & 30536 & 44 \\
\hline Sakarya & 11573 & 494 & 13995 & 20 \\
\hline Samsun & 8426 & 293 & 10219 & 21 \\
\hline Şanlıurfa* & & 690 & & \\
\hline Tekirdağ & 20393 & 239 & 24427 & 19 \\
\hline Trabzon & 18680 & 361 & 29166 & 56 \\
\hline Van & 31208 & 317 & 34854 & 11 \\
\hline
\end{tabular}

*illerin belirtilen günlerdeki takipçi sayılarına ulaşılamamıştır.

Tablo 3'de büyükşehir belediyelerinin 13 Mart-01 Haziran 2020 tarihleri arasında yaptıkları paylaşım sayılarına ve bu tarihlerdeki takipçi sayıları ile artış oranlarına yer verilmiştir. Her iki tarih için de en çok takipçisi olan büyükşehir belediyesi İstanbul iken, en az takipçiye sahip büyükşehir belediyesi Samsun'dur. Bu tarihler arasında en çok paylaşımı 938 tweet ile Mardin Büyükşehir Belediyesi yaparken en az paylaşımı 58 tweet ile Aydın Büyükşehir Belediyesi yapmıştır. Takipçi sayılarındaki artış oranında ise 361 tweet paylaşan Trabzon Büyükşehir Belediyesi \%56 ile ilk sırada yer alırken 420 tweet paylaşan Bursa Büyükşehir Belediyesi $\% 4$ ile son sırada yer almaktadır. Buradan paylaşım sayısı ile takipçi oranındaki artışın orantılı olmadığı çıkarımı 
yapılabilmektedir. Belirtilen günlerdeki takipçi sayısı verilerine ulaşılamayan Kahramanmaraş, Manisa, Mardin ve Şanlıurfa büyükşehir belediyeleri bu analizlerde yer almamıştır.

Araştırmada 30 büyükşehir belediyesinin 13 Mart-01 Haziran 2020 tarihleri arasında Twitter hesaplarından yapılan paylaşımlar Nvivo analiz programı yardımıyla kodlanarak kategoriler oluşturulmuş ve analiz yapılmıştır. Yapılan paylaşımların bu kategoriler özelindeki genel görünümü Tablo 4'de verilmiştir.

Tablo 4. Büyükşehir Belediyeleri Genel Görünüm

\begin{tabular}{lll}
\hline Tweet Konusu & Tweet Sayısı & Yüzde \\
\hline Başkandan Retweet & 2936 & 21.6 \\
Kurumsal Faaliyetler & 3010 & 22.2 \\
Koronavirüs & 2262 & 16.6 \\
Sosyo-Kültürel & 1450 & 10.7 \\
Duyuru-Bilgilendirme & 2234 & 16.4 \\
Taziye, Anma ve Kutlama & 1065 & 7.8 \\
Ramazan Ayı Temalı & 408 & 3 \\
Hava Durumu & 144 & 1.1 \\
İlan & 86 & 0.6 \\
Toplam & 13595 & 100 \\
\hline
\end{tabular}

30 büyükşehir belediyesinde toplam 13595 tweet analize tabi tutulmuştur. Genel görünümde "Kurumsal Faaliyetler" ve "Başkandan Retweet" başlıkları ön plana çıkmaktadır. Daha sonra ise "Koronavirüs" ve "Duyuru-Bilgilendirme" temalı tweetler yoğunluktadır. 
Tablo 5. Büyükşehir Belediyeleri Ayrntılı Kategori Görünümü

\begin{tabular}{|c|c|c|c|c|c|c|}
\hline & $\begin{array}{l}\text { Başkandan } \\
\text { Retweet }\end{array}$ & $\begin{array}{l}\text { Kurumsal } \\
\text { Faaliyet }\end{array}$ & Koronavirüs & $\begin{array}{l}\text { Sosyo- } \\
\text { Kültürel }\end{array}$ & $\begin{array}{l}\text { Duyuru- } \\
\text { Bilgilendirme }\end{array}$ & $\begin{array}{l}\text { Taziye, Anma } \\
\text { ve Kutlama }\end{array}$ \\
\hline Adana & $38(\% 15,09)$ & $49(\% 20,40)$ & $60(\% 25,00)$ & $25(\% 10,40)$ & $28(\% 11,60)$ & $40(\% 16,70)$ \\
\hline Ankara & $200(\% 22,40)$ & $220(\% 24,60)$ & $100(\% 11,20)$ & $73(\% 8,20)$ & $170(\% 19,00)$ & $44(\% 4,90)$ \\
\hline Antalya & $53(\% 25,80)$ & $49(\% 23,90)$ & $7(\% 3,40)$ & 0,00 & $84(\% 41,00)$ & $12(\% 5,90)$ \\
\hline Aydın & 0,00 & $22(\% 38,00)$ & $19(\% 32,70)$ & $1(\% 1,70)$ & $4(\% 6,90)$ & $12(\% 20,70)$ \\
\hline Balıkesir & $50(\% 18,10)$ & $39(\% 14,10)$ & $48(\% 17,40)$ & $66(\% 23,90)$ & $42(\% 15,20)$ & $31(\% 11,30)$ \\
\hline Bursa & $81(\% 19,30)$ & $115(\% 27,40)$ & $62(\% 14,80)$ & $38(\% 9,00)$ & $96(\% 22,80)$ & $28(\% 6,70)$ \\
\hline Denizli & $131(\% 32,50)$ & $69(\% 17,00)$ & $78(\% 19,30)$ & $48(\% 11,90)$ & $35(\% 8,70)$ & $43(\% 10,60)$ \\
\hline Diyarbakır & $244(\% 30,90)$ & $151(\% 19,10)$ & $161(\% 20,40)$ & $40(\% 5,10)$ & $149(\% 18,80)$ & $45(\% 5,70)$ \\
\hline Erzurum & $14(\% 6,30)$ & $28(\% 12,60)$ & $56(\% 25,20)$ & $42(\% 18,90)$ & $32(\% 14,40)$ & $50(\% 22,60)$ \\
\hline Eskişehir & $41(\% 13,30)$ & $64(\% 20,70)$ & $68(\% 22,00)$ & $37(\% 12,00)$ & $75(\% 24,30)$ & $24(\% 7,70)$ \\
\hline Gaziantep & $29(\% 3,50)$ & $131(\% 15,90)$ & $145(\% 17,70)$ & $225(\% 27,40)$ & $127(\% 15,50)$ & $62(\% 7,60)$ \\
\hline Hatay & $57(\% 16,60)$ & $135(\% 39,30)$ & $42(\% 12,20)$ & $42(\% 12,20)$ & $40(\% 11,60)$ & $28(\% 8,10)$ \\
\hline İstanbul & $228(\% 32,60)$ & $177(\% 25,30)$ & $49(\% 7,00)$ & $86(\% 12,30)$ & $131(\% 18,70)$ & $29(\% 4,10)$ \\
\hline İzmir & $110(\% 29,40)$ & $84(\% 22,50)$ & $52(\% 13,90)$ & $42(\% 11,20)$ & $59(\% 15,80)$ & $27(\% 7,20)$ \\
\hline Kahramanmara & ş169 (\%21,40) & $123(\% 15,50)$ & $104(\% 13,10)$ & $123(\% 15,50)$ & $108(\% 13,60)$ & $33(\% 4,20)$ \\
\hline Kayseri & $195(\% 43,00)$ & $103(\% 22,80)$ & $50(\% 11,00)$ & $19(\% 4,20)$ & $59(\% 13,00)$ & $27(\% 6,00)$ \\
\hline Kocaeli & $229(\% 24,40)$ & $229(\% 24,40)$ & $200(\% 21,40)$ & $95(\% 10,10)$ & $113(\% 12,20)$ & $34(\% 3,70)$ \\
\hline Konya & $104(\% 22,10)$ & $62(\% 13,20)$ & $47(\% 9,90)$ & $113(\% 23,90)$ & $63(\% 13,40)$ & $29(\% 6,20)$ \\
\hline Malatya & $124(\% 23,50)$ & $86(\% 16,30)$ & $88(\% 16,60)$ & $37(\% 7,00)$ & $58(\% 11,00)$ & $10(\% 20,30)$ \\
\hline Manisa & $98(\% 36,60)$ & $52(\% 19,40)$ & $40(\% 14,90)$ & $8(\% 3,00)$ & $34(\% 12,70)$ & $36(\% 13,40)$ \\
\hline Mardin & 0,00 & $379(\% 40,40)$ & $277(\% 29,50)$ & $63(\% 6,70)$ & $146(\% 15,60)$ & $55(\% 5,90)$ \\
\hline Mersin & $97(\% 41,80)$ & $27(\% 11,60)$ & $22(\% 9,50)$ & $50(\% 21,60)$ & $30(\% 12,90)$ & $6(\% 2,60)$ \\
\hline Muğla & $60(\% 33,90)$ & $22(\% 12,40)$ & $35(\% 19,80)$ & $11(\% 6,20)$ & $29(\% 16,40)$ & $20(\% 11,30)$ \\
\hline Ordu & $110(\% 31,50)$ & $90(\% 25,80)$ & $46(\% 13,20)$ & $42(\% 12,00)$ & $38(\% 10,90)$ & $14(\% 4,00)$ \\
\hline Sakarya & $30(\% 6,10)$ & $125(\% 25,30)$ & $90(\% 18,20)$ & $40(\% 8,10)$ & $104(\% 21,00)$ & $39(\% 7,90)$ \\
\hline Samsun & $5(\% 1,70)$ & $90(\% 30,70)$ & $56(\% 19,10)$ & $10(\% 3,40)$ & $62(\% 21,20)$ & $70(\% 23,90)$ \\
\hline Şanlıurfa & $174(\% 25,20)$ & $103(\% 14,90)$ & $91(\% 13,20)$ & $48(\% 7,00)$ & $163(\% 23,60)$ & $33(\% 4,80)$ \\
\hline Tekirdağ & $84(\% 35,50)$ & $42(\% 17,60)$ & $54(\% 22,60)$ & 0,00 & $40(\% 16,70)$ & $19(\% 7,90)$ \\
\hline Trabzon & $93(\% 25,80)$ & $55(\% 15,20)$ & $55(\% 15,20)$ & $26(\% 7,20)$ & $51(\% 14,20)$ & $52(\% 14,40)$ \\
\hline Van & $88(\% 27,80)$ & $89(\% 28,00)$ & $60(\% 19,00)$ & 0,00 & $64(\% 20,20)$ & $16(\% 5,00)$ \\
\hline
\end{tabular}

Tablo 5'de tüm büyükş̧ehir belediyelerinin paylaşımlarının kategorik dağılımı bir arada verilmiştir. İlgili tabloda belediyeler tarafından daha az paylaşım yapılan "Ramazan Ayı Temalı", "İlan" ve "Hava Durumu" kategorileri bulunmamaktadır. İlgili tabloya göre kategorilerin değerlendirilmeleri aşağıda yapılmıştır.

"Başkandan Retweet" kategorisinde belediyelerin hesabında belediye başkanının paylaşımlarına yer verilme sayıları bulunmaktadır. Bu kategorideki paylaşımların genel paylaşımlar içerisindeki oranı \%21,6'dır. Paylaşımlarında belediye başkanının tweetlerine en çok yer veren belediyeler \%43 ile Kayseri ve \%41,8 ile Mersin'dir. Belediye başkanının tweetlerine hiç yer vermeyen iki belediye bulunmaktadır. Bunlar Aydın ve Mardin'dir. Aydın Büyükşehir Belediyesi'nin toplam 
paylaşım sayısının az olması ve Mardin Büyükşehir Belediyesi'nin ilgili tarihler aralığında belediye başkanlığı görevini vekaleten yürüten Mardin Valisi Mustafa YAMAN'in 09 Haziran 2020'de görev yerinin değişmesi bu durumu açıklamaktadır.

"Kurumsal Faaliyet" kategorisinde kurum bünyesinde yapılan çalışmalar, yapım-onarım işleri, sosyal yardımlar gibi içeriğe sahip olan paylaşımlar değerlendirilmiştir. En fazla paylaşım yapılan kategori olup tüm paylaşımlar içerisinde $\% 22,2$ 'lik orana sahiptir. Paylaşımlarında bu kategoriye en fazla yer veren belediyeler \%40,4 ile Mardin ve \%39,3 ile Hatay'dır. Bu kategoride en az paylaşım yapan belediye ise \%11,6 ile Mersin'dir.

"Koronavirüs" kategorisinde dezenfekte çalışmaları, karantina bölgeleri gibi doğrudan koronavirüse yönelik bilgileri içeren paylaşımlar değerlendirilmiştir. Her belediyenin aktif olarak kullandığ kategorinin genel paylaşımlar içerisindeki ağırlığı \%16,6'dır. Paylaşımlarında bu kategoriye en fazla yer veren belediyeler \%32,7 ile Aydın ve \%29,5 ile Mardin olmuştur. Bu kategoride oran olarak en az paylaşım yapan belediyeler ise \%3,4 ile Antalya ve \%7 ile İstanbul'dur.

"Duyuru-Bilgilendirme" kategorisinde belediyenin yapmış olduğu duyurular, il hıfzıssıhha kurulu kararları, yasaklara ilişkin bilgiler, dijital canlı yayın bilgileri, otobüs güzergâhları gibi paylaşımlar değerlendirilmiştir. Tüm paylaşımlar içerisinde \%16,4'lük orana sahiptir. Paylaşımlarında bu kategoriye en çok yer veren belediyeler \%41 ile Antalya ve \%24,3 ile Eskişehir'dir. En az paylaşım oranına sahip belediyeler ise \%6,9 ile Aydın ve \%8,7 ile Denizli'dir.

"Sosyo-Kültürel" kategorisinde kentin kültürel değerlerine, sosyal yaşama ya da pandemi özelinde evde yapılabilecek sosyal etkinliklere yönelik paylaşımlar değerlendirilmiştir. Tüm paylaşımlar içerisindeki ağırlığı \%10,7'dir. Paylaşımlarında bu kategoriye en fazla yer veren belediye \%27,4 ile Gaziantep'tir. Bu kategoride hiç paylaşım yapmayan üç belediye bulunmaktadır. Bunlar; Antalya, Tekirdağ ve Van Büyükşehir Belediyeleridir.

“Taziye, Anma ve Kutlama" kategorisinde dini ve resmî gün kutlamaları, şehit taziyeleri, ölüm yıldönümlerine yönelik yapılan paylaşımlar değerlendirilmiştir. Tüm paylaşımlar içerisindeki oranı 
$\% 7,8^{\prime}$ dir. Paylaşımlarında bu kategoriye en fazla yer veren belediye $\% 23,9$ ile Samsun iken en az yer veren belediye \%2,6 ile Mersin' dir.

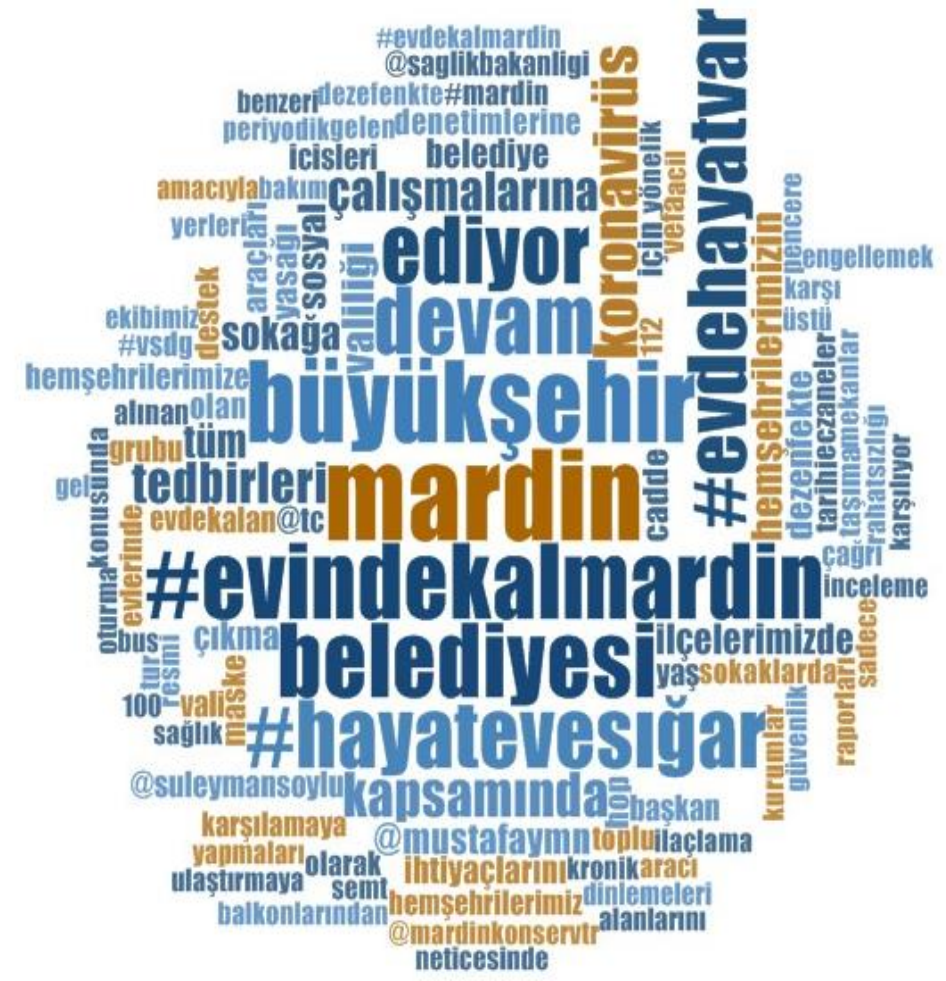

Resim 1. Mardin Büyükşehir Belediyesi WordCloud Görünümü

Mardin Büyükşehir Belediyesi'nin paylaşımları Tablo 5' de görüleceği üzere "Kurumsal Faaliyet" ve "Koronavirüs" kategorilerinde ağırlık göstermektedir. Belediyenin paylaşımlarına ilişkin WordCloud görünüm incelendiğinde ise belediye ismi, "büyükşehir çalışmalarına devam ediyor" ifadesi ve "\#evindekalmardin" etiketi ana unsurlar olarak görünmektedir. Bunun yanında yine Covid-19 pandemisi temalı etiket ve terimler bulunmaktadır. 


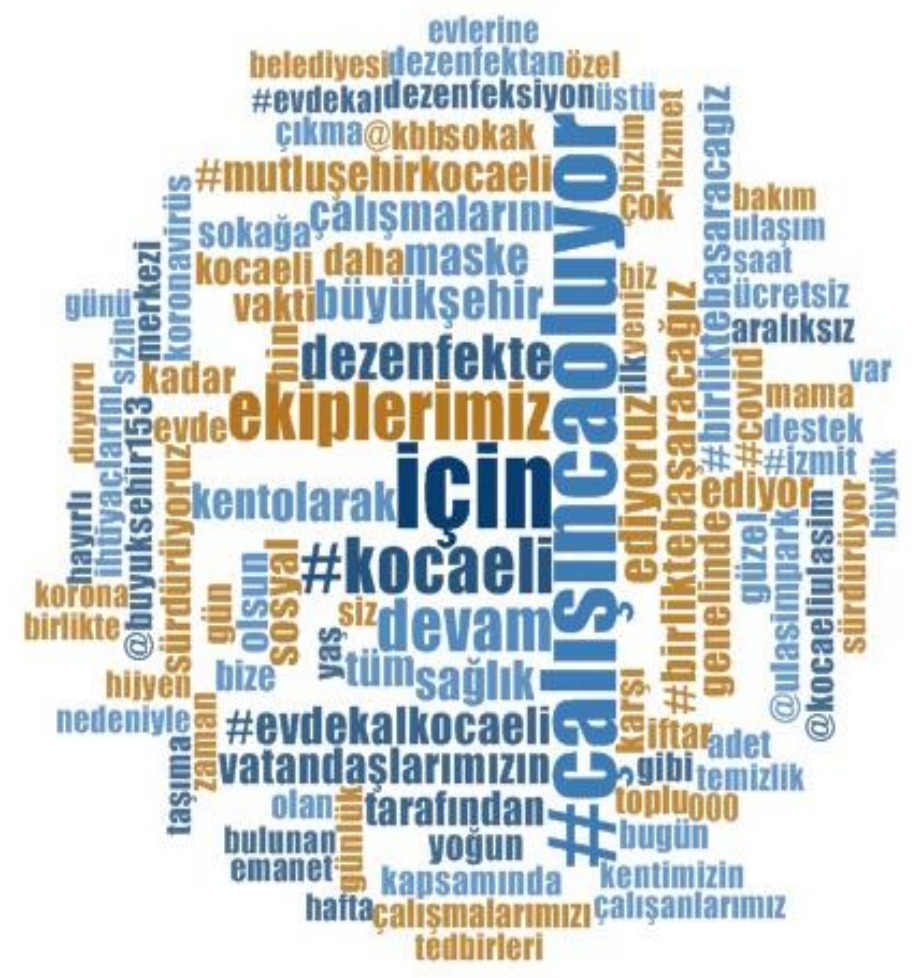

Resim 2. Kocaeli Büyükşehir Belediyesi WordCloud Görünümü

Kocaeli Büyükşehir Belediyesi'nin paylaşımları Tablo 5'de görüleceği üzere "Başkandan Retweet", "Kurumsal Faaliyet" ve "Koronavirüs" kategorilerinde ağırlık göstermektedir. Kocaeli Büyükşehir Belediyesi'nin paylaşımlarına ait WordCloud görünümde ise "Kurumsal Faaliyet" kategorisine yönelik "\#çalışıncaoluyor" etiketi ön plandadır. Bunun yanında “\#kocaeli" etiketi ve Covid-19 pandemisine yönelik terimler bulunmaktadır. 


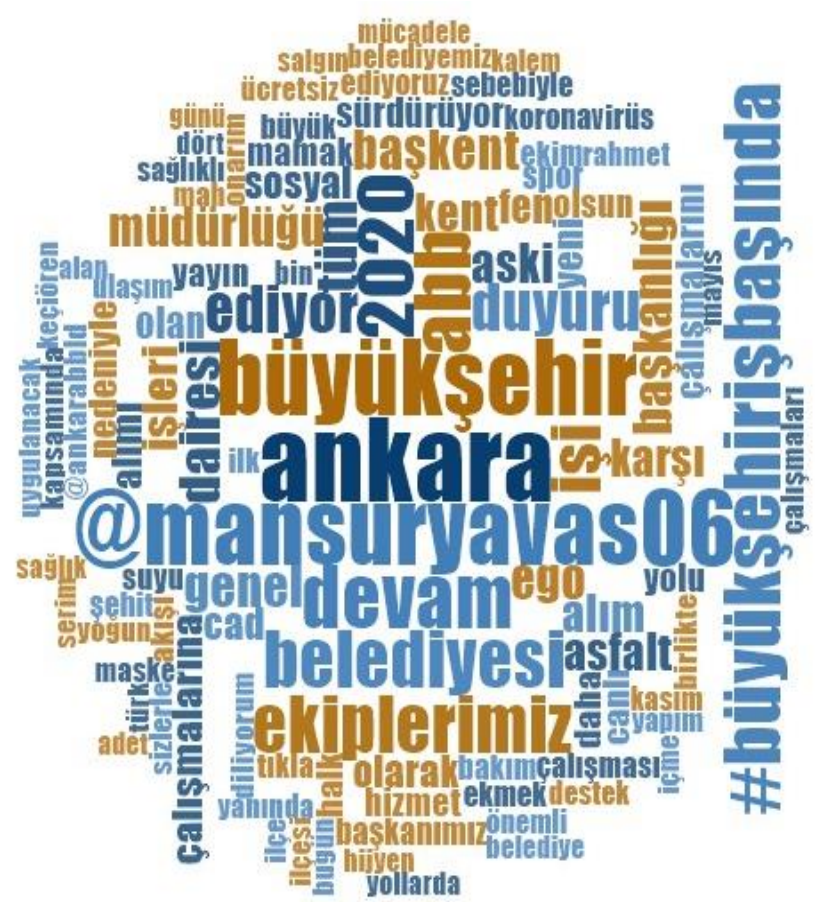

Resim 2. Ankara Büyükşehir Belediyesi WordCloud Görünümü

Ankara Büyükşehir Belediyesi'nin paylaşımları Tablo 5'de görüleceği üzere "Başkandan Retweet" ve "Kurumsal Faaliyet" kategorilerinde ağırlık göstermektedir. Ankara Büyükşehir Belediyesi'nin yaptığ1 paylaşımların WordCloud görünümü incelendiğinde Belediye Başkanı Mansur YAVAŞ'ın kullanıcı adı ve belediyenin kurumsal faaliyetlerle ilgili paylaşımlarda kullandığı etiket dikkat çekmektedir. Pandemi dönemiyle ilgili koronavirüs, salgın gibi terimler az miktarda kullanılmıştır.

\section{Sonuç}

Örgütlerin ayakta kalması ve doğru yönetilmesi için bilimsel olarak yürütülen halkla ilişkiler faaliyetlerinin önemi büyüktür. Halkla ilişkilerin bu konumu sadece özel kuruluşlar için değil kamu kurumları için de geçerli bir değerlendirmedir. Kamu kurumları içerisinde başarılı 
halkla ilişkiler çalışmalarına daha çok yerel yönetim birimleri ihtiyaç duymaktadırlar. Bu ihtiyaç şüphesiz yerel yönetimlerin, kanunda belirtildiği üzere, seçmenler tarafından seçilerek oluşturulmaları ve halka en yakın kamu kurumları olmalarından kaynaklanmaktadır. Böyle bir değerlendirmede yerel yönetim birimlerinin halkla ilişkiler faaliyetlerini titizlikle yürütmeleri ve bu faaliyetlerin sonuçlarına göre yeni politikalar belirlemeleri yönetimsel bir zorunluluktur.

Günümüzde halkla ilişkiler faaliyetleri çoğunlukla dijital ortamlarda yürütülmektedir. İnsanlarla hızlı, ucuz ve kitlesel iletişim kurma özelliğine sahip olan sosyal medya platformları dijital ortamlarda örgütler tarafından en çok tercih edilen araçlardandır. Yerel yönetim birimleri de sosyal medya platformlarına kayıtsız kalmamışlardır. Bir yerel yönetim birimi olarak büyükşehir belediyelerinin halkla ilişkiler faaliyetlerinde sosyal medyanın yerinin incelendiği bu çalışmada yukarıda verilen bulgular ışığında çalışma soruları dikkate alınarak şu değerlendirmeler yapılmıştır.

Çalışmadaki sayısal verilere bakıldığında bir belediye günde ortalama 5,7 paylaşım yapmıştır. Bu durum büyükşehir belediyelerinin iletişim aracı olan Twitter'ı aktif olarak kullandıklarını göstermektedir. Ayrıca çalışmanın yapıldığı dönemde büyükşehir belediyelerinin yaptıkları paylaşım sayısı, önceki eşit aralıklı döneme göre \%30,3 artmıştır. Bu oran Twitter'ın pandemi döneminde büyükşehir belediyeleri tarafından daha fazla kullanıldığını göstermektedir.

Çalışmanın odak noktasında bulunan ve bütün belediyelerin paylaşımlarında yer verdiği "Koronavirüs" kategorisi tüm paylaşımlar içerisinde \%16,6'l1k orana sahiptir. Altı ana kategorili bir değerlendirmede bu oranın ortalama bir gündem olduğu görülmektedir. Ancak değerlendirmeye tabi tutulan diğer beş kategorinin kalıplaşmış temalar olması ve "Koronavirüs" temasının en fazla paylaşım yapılan üçüncü kategori olması, büyükşehir belediyelerinin Twitter kullanımlarının olağanüstü bir döneme ilişkin gündeme kayıtsız kalmadığını göstermektedir.

"Kurumsal Faaliyet" kategorisindeki paylaşımlar, yapılan çalışmaların halka duyurulması açısından belediyenin reklamı olarak görülebilir. "Başkandan Retweet" kategorisi de bu amaç içerisinde değerlendirilirse iki kategori toplamda \%43,8'lik bir orana sahiptir. Bu 
oran kurumu halka tanıtmak amacıyla Twitter'ın halkla ilişkiler aracı olarak kullanıldığını göstermektedir.

"Duyuru-Bilgilendirme" kategorisi değerlendirilecek olunursa, bu kategori $\% 16,4^{\prime}$ lük bir orana sahiptir. Bu oran Twitter'ın büyükşehir belediyeleri tarafından önemli mesajları halka iletmek amacıyla kullanıldığını göstermektedir.

Son olarak en fazla paylaşım yapan üç belediyenin WordCloud görünümlerinden hareketle; kategorilerde oluşan sayısal ağırlıkların içeriklerde kullanılan kelimelerle doğru orantılı ve uyum içinde olduğu söylenebilir.

$\mathrm{Bu}$ doğrultuda yerel yönetimler, halkla ilişkiler faaliyetlerinde doğrudan ve anında etkileşime ulaşabilecekleri dijital platformu iyi analiz etmelidir. Sosyal medyanın gücünün farkından olan ve bunu iyi kullanabilen yerel yönetim birimleri kendilerini anlatma ve halkı anlama konusunda önde olacaklardır. Sosyal medya ekseninde bundan sonra yapılacak çalışmalarda, sosyal medyanın hem kişiler hem kurumlar için iletişim aracı olarak bir seçenekten bir ihtiyaca/zorunluluğa dönüşüp dönüşmediği tartışılabilir. Bunun yanında nüfus bakımından benzer ölçekte olan büyükşehir belediyelerinin sosyal medya kullanma sıklıkları ve sosyal medya üzerinden halka ulaşabilme durumları karşılaştırmalı olarak çalışılabilir ve yerel seçimlere yansıması değerlendirilebilir. 


\title{
EXTENDED ABSTRACT
}

\section{The Use of Social Media as a Public Relations Tool During the Pandemic by Metropolitan Municipalities}

\author{
Şerife Pekküçükşen- Balı Yıldırım \\ Karamanoğlu Mehmetbey University
}

In this study, the concepts of public relations and social media are emphasized and the importance of these concepts in terms of local governments is mentioned. In thepractice of the study, a research on the use of social media for public relations in local government entities was referred. It would be appropriate to touch briefly on the concepts presented detailed in the study and the practice here.

The term of public relations has gained a different dimension with the development of communication technologies. With the technological developments that allow cheap and fast communication, competition in many economic, political and administrative fields has reached the highest phase. The formation of this competitive environment has made public relations a necessity, in parallel with technological developments, increasing communication opportunities have increased the applicability of public relations. From the public relations point of view, the most important of these technological developments is undoubtedly the internet. The Internet, with its integrated media feature, is the most important and most advanced communication tool that technology offers to the whole world and even to public relations, as it enables cheap, fast and mutual communication. The internet, which offers the chance to practice recognition, promotion and mutual communication, which is the purpose of public relations, in the large masses it reaches, is a new window in the name of public relations. Organizations that want to take advantage of these opportunities are also shifting their public relations work to digital environments. Social media platforms are one of the most important tools that organizations use in the digital environment for this purpose. Today, social media platforms are platforms that target 
audiences actively use and are in constant communication with. The adoption by people and the rapid increase in its use in society have turned social media into an important tool to reach the public. Today, both private and public institutions use social media widely in their public relations studies. The study focused on local governments, which are public institutions.

Local governments have an important structure in the public administration organizations of states. This importance is due to the fact that local governments are somewhere between the central government and the public. Local governments have a significant share in reaching the bottom of the central government and in communicating the demands of the people to the central organization. In addition to these duties, the closeness of local governments to the public and the increasing demands for participatory democracy today necessitate public relations in local governments. Apart from these, the response of the people to the government, including the central government, and the feedback they expect from the government are again the local government units. This situation necessitates local governments to establish a strong communication with the public. Today, local government units carry out professional public relations practices in order to make this communication healthy and efficient. One of the tools that local governments use for public relations activities is social media platforms.

Based on this, the aim of the study is to reveal the use of social media as a public relations tool of metropolitan municipalities during extraordinary periods. The study is important in terms of examining the effect of social media on public relations, the level of use of social media by public institutions and the frequency ofusing social media in order to inform and guide the public in extraordinary times. Considering these, the main theme of this research is local government units, and its sample is metropolitan municipalities. The research is basically based on the assumption that "metropolitan municipalities use social media as apublic relations tool". In the research, the shares made by metropolitan municipalities on Twitter were filtered according to the constraints and classified under certain categories andanalyzed. Six main categories were 
used in the study, and different additional categories specific to the municipality were also included.

Within the framework of the findings obtained, the level of using social media as a public relations tool by all metropolitan municipalities in Turkey was examined and the social media organizations of metropolitan municipalities, the intensity of the feedback from the target audience and the extent to which these feedbacks were evaluated were tried to be explained.

As a result, during the Covid-19 pandemic period, thirty metropolitan municipalities in Turkey used Twitter for public communication. While 13595 shares were shared between these dates, the average number of tweets shared per day was 5.79. As with all social media platforms, this shows that Twitter's feature, which allows direct and fast communication with the public, is actively used by metropolitan municipalities

\section{Kaynakça/References}

Acar, M. (1993). Belediyelerde halkla ilişkiler. Ankara: Devlet Planlama Teşkilatı.

Asna, A. (2006). Kuramda ve uygulamada halkla ilişkiler. İstanbul: Pozitif Yayınları.

Asna, M. A. (1997). Halkla ilişkiler dünden bugüne bir sanat-meslek öyküsü. İstanbul: Yön Matbaacilık.

Aydın, A. H. ve Taş, İ. E. (2016). Kamu yönetiminde halkla ilişkiler. Ankara: Seçkin Yayınları.

Eryılmaz, B. (2017). Kamu yönetimi. Kocaeli: Umuttepe Yayınları.

Grunig, J. E. (2009). Paradigms of global public relations in an age of digitalisation. PRism, 6(2), 1-19.

Karadeniz, M. (2008). Yerel yönetimlerde halkla ilişkiler faaliyetleri ve bir uygulama (Çanakkale Belediyesi Örneği). Doktora tezi.Marmara Üniversitesi, Sosyal Bilimler Enstitüsü, İşletme Ana Bilim Dalı, İstanbul.

Kazanc1, M. (2013). Kamuda ve özel kesimde halkla ilişkiler. Ankara: Turhan Kitabevi.

Mıhçıŏlu, C. (1970). Halkla ilişkiler nedir? Ankara Üniversitesi Eğitim Bilimleri Fakültesi Dergisi, 3(1), 91-108.

Okay, A. ve Okay, A. (2014). Halkla ilişkiler ve medya. İstanbul: Derin Yayınları. 
Peltekoğlu, F. B. (2016). İletişimin gücü kurumsaldan küresele halkla ilişkiler. İstanbul: Beta Basın Yayın Dağıtım.

Selvi, Ö. ve Şentürk, Z. A. (2019). Halkla ilişkiler ve uygulama alanları. Konya: Eğitim Yayınevi.

Tortop, N. ve Özer, M. A. (2017). Halkla ilişkiler. Ankara: Nobel Akademik Yayıncilik.

Vicari, S. (2012). Protests for global change on Twitter: The cas of \#15oct in Italy. From Social to Political: New Forms of Mobilization and Democratization (Conference Proceedings).

We Are Social (2020). Global digital overview. 14 Şubat 2021 tarihinde https://wearesocial.com/digital-2020 adresinden erişildi.

Yayınoğlu, P. E. (2007). Yerel yönetimlerde halkla ilişkiler belediyeler yönünden bir değerlendirme. İstanbul: Birsen Yayınevi.

Yıldırım, S. (2015). Yerel yönetim ve Demokrasi. İstanbul: Marmara Belediyeler Birliği Kültür Yayınları.

\section{Kaynakça Bilgisi / Citation Information}

Pekküçükşen, Ş. ve Yıldırım, B. (2021).Pandemi sürecinde Büyükşehir Belediyelerinin halkla ilişkiler aracı olarak sosyal medya kullanımı.OPUS-Uluslararası Toplum Araştırmaları Dergisi, 18(43), 6708-6731. DOI: 10.26466/opus.898016. 